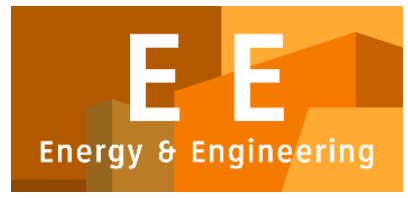

PAPER - OPEN ACCESS

\title{
Studi Sistem Lingkungan Penunjang Kehidupan Perumahan Sederhana Berkelanjutan
}

\author{
Author \\ : Nelson Siahaan \\ DOI \\ : $10.32734 /$ ee.v1i1.111 \\ ISSN \\ : 2654-7031 \\ E-ISSN \\ : 2654-704X
}

Volume 1 Issue 1 - 2018 TALENTA Conference Series: Energy and Engineering

\section{(a) $(\mathbb{\theta})$}

This work is licensed under a Creative Commons Attribution-NoDerivatives 4.0 International License.

Published under licence by TALENTA Publisher, Universitas Sumatera Utara
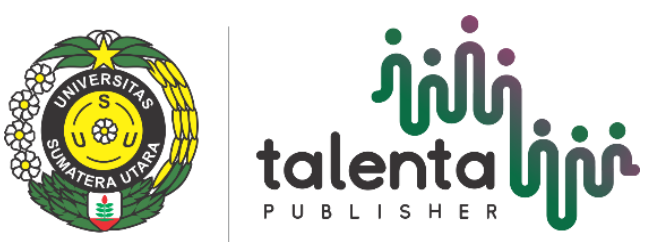


\title{
Studi Sistem Lingkungan Penunjang Kehidupan Perumahan Sederhana Berkelanjutan
}

\author{
Nelson Siahaan ${ }^{\mathrm{a}}$ \\ ${ }^{a}$ Fakultas Teknik, Universitas Sumatera Utara, Medan 20155 \\ nelson@usu.ac.id
}

\begin{abstract}
Abstrak
Masyarakat selalu berkeinginan mengatur lingkungan rumahnya melalui dua alat biasa digunakan yaitu; properti dan desain. Data menunjukkan bahwa kurun waktu tahun 2007 sampai tahun 2016, 87\% rumah atau 2873 unit rumah di Perumnas Martubung I Medan yaitu; rumah tipe 29, tipe 36 dan tipe 54 melakukan transformasi fisik berupa; restorasi, renovasi, ataupun rekonstruksi. Transformasi ini menghasilkan karbon melalui emisi CO2 setara 2.895 ton.C [15]. Studi bagaimana sistem lingkungan penunjang kehidupan di Perumahan Martubung I membentuk perumahan sederhana berkelanjutan perlu dilakukan akibat dinamika pertumbuhan dan urbanisasi tinggi. Penelitian ini berangkat dari pemahaman adanya hubungan yang kompleks diantara semua komponen sistem lingkungan penunjang kehidupan perumahan sederhana yang mendorong transformasi bentuk rumah di Perumnas Martubung I. Perumnas Martubung I dipilih karena sejak dibangun tahun 2006 dalam kurun waktu 20 tahun terdapat $87 \%$ rumah mengalami berbagai transformasi fisik rumah.Data diperoleh melalui observasi, wawancara dan kuesioner pada penghuni rumah. Analisa deskriptif dalam bentuk tabel frekuensi, persentase dan grafik, analisis korelasi untuk memprediksi komponen-komponen yang paling mempengaruhi perumahan berkelanjutan.Berbagai faktor penentu keputusan transformasi diidentifikasi dalam studi ini. Studi ini kelak akan mampu membuat strategi bagi kemungkinan skenario-skenario inovatif dan orisinal untuk mengendalikan perubahan bentuk desain rumah di perumahan sederhana berkelanjutan.
\end{abstract}

Kata Kunci: sistem; lingkungan; penghuni; rumah; perumahan sederhana

\section{Pendahuluan}

Lingkungan Binaan (Built Environment) adalah salah satu sektor paling besar menghasilkan emisi CO2, salah satu gas buang penyebab pemanasan global. Disektor ini, perumahan perkotaan adalah salah satu penyumbang emisi terbesar. Populasi penduduk perkotaan dan pertumbuhan urbanisasi cukup tinggiserta harapan usia penduduk kota bertambah secara keseluruhan,tentu membutuhkanpenyelenggaraan perumahan berkelanjutan [3]. Lima tahun kedepan Indonesia merencanakan membangun 1,367 juta unit rumah bersubsidi, memberi fasilitas kredit bagi 1,94 juta konstruksi rumah terencana dan 1,2 juta unit rumah dibangun sendiri serta membantu peningkatan dari 1,35 juta unit rumah. Rencana ini tentu memunculkan 2 (dua) pertanyaan mendasar yaitu: pertama, akankah pembangunan permukiman dan perumahan skala besar ini dapat berkelanjutan? Kedua, apa dampaknya bagi kota yang berkelanjutan? Pertanyaan-pertanyaan ini menghadirkan sejumlah tantangan dan kesulitan penanganan mengingat kota-kota saat ini tumbuh dan berkembanng semakin kompleks, sehingga perumahan berkelanjutan sendiri semakin rumit masalahnya [5]. 
Penelitian dilakukan [15] menunjukkan bahwa berbagai komponen dari perumahan sederhana di Perumnas Martubung I Medan menghasilkanemisi $\mathrm{CO} 2$ melalui tindak restorasi, renovasi maupun rekonstruksi hunian. Berbagai transformasi hunian ini memakai sumber daya cukup besar mulai dari pembuatan material bangunan, distribusi bahan bangunan, jumlah pekerja yang terlibat, transportasi dan kegiatan rumah tangga sehari-hari (Puslitbangkim, 2007). Data menunjukkan bahwa dari tahun 1995 sampai dengan tahun 2009, 80\% rumah atau 2830 unit rumah; baik rumah tipe 29, tipe 36 maupun tipe 54 seluruhnya menghasilkan emisi CO2 ke udara setara 2.895 ton C melalui transformasi bentuk rumah [15]1

Seluruh transformasi fisik adalah suatu sistem interrelasi kompleks dari berbagai komponen sistem perumahan akibat pemanfaatan ruang kawasan perumahan dan dengan melibatkan penggunaan energi fosil cukup besar ([10]; Puslitbangkim, 2007; [15]). Transformasi dapat dikendalikan melalui pendekatan rancangan seperti pengaturan; sistem ventilasi udara, ketinggian bangunan, luasan bidang bukaan vertikal, denah bangunan, koefisien dasar bangunan, persentase peruntukan lahan, sistem sirkulasi perumahan, ruang terbuka hijau, garis sempadan bangunan, dan penggunaan energi rumah tangga minimal (Syahrin, 2003;[4]; [6]). Biasanya emisiCO2 dihasilkan dari pemakaian bahan bakar fosil selama konstruksi, dan sebagian berhubungan dengan pabrikasi dan transportasi bahanbahan konstruksi ([13];[6]). Selain itu, kegiatan rumah tangga juga melepaskan gas CO2 ke udara melalui pemakaian energi yang bersumber dari pembakaran bahan bakar dan penggunaan listrik [7]. Lebih jauh, sirkulasi lalu lintas pada perumahan dan perubahan gaya hidup juga memberi kontribusi pada terciptanya perumahan berkelanjutan (Puslitbangkim, 2007).

Hal yang dimaksud dengan perumahan berkelanjutan dalam penelitian ini adalah perumahan yang memiliki dampak negatif lingkungan, sosial, dan ekonomi minimal dalam hubungannya dengan perubahan iklim (gas rumah kaca); kualitas udara, air, dan tanah; kebisingan; bau, penggunaan bahan-bahan tidak dapat diperbaharui; dan keaneka-ragaman hayati. Perumahan yang memiliki dampak negatif lingkungan, sosial, dan ekonomi minimal berkaitan erat dengan aspek-aspek sistem lingkungan penunjang kehidupanperumahan berkelanjutan seperti; pola jalan perumahan, pedestrianisasi, ruang terbuka hijau, danau/kolam buatan, garis sempadan bangunan, material bangunan, luasan bidang bukaan vertikal, penggunaan energi minimal untuk menunjang aktifitas rumah tangga, lokasi pembuangan sampah,perbandingan antara luas area terbangun dengan lahan terbuka hijau ([14]; Puslitbangkim, 2007).

Penelitian ini mengkaji sistem lingkungan penunjang kehidupan perumahan berkelanjutan pada perumahan sederhana di Perumnas Martubung I Medanagar diperoleh suatu pengetahuan (knowledge) tentang perilaku dari berbagai hubungan yang komplekskomponen-komponensistem lingkungan penunjang kehidupan perumahan sederhana. Penelitian kualitatif dilakukan untuk membangun suatu model hubungan simpal kausal berbagai komponen dari sistem lingkungan penunjang kehidupan perumahan berkelanjutan di Perumahan Martubung I Medan.Selanjutnya, dari studi dapat diketahui komponen-komponen apa yang paling dominan mempengaruhi keberlanjutan pada perumahan sederhana.Oleh karena itu, jika interrelasi dari komponen-komponen sistem lingkungan penunjang kehidupan perumahan sederhana berkelanjutan dapat digambarkan maka akan dapat dirumuskan kebijakan pembangunan perumahan sederhana berkelanjutan yang efisien dan efektif.

\section{Metode Penelitian}

Anggapan awal penelitian ini adalah bahwa sumber ketidak-berlanjutan suatu perumahan adalah tingginya emisi $\mathrm{CO}^{2}$ berasal dari beberapa faktor yaitu;pra-konstruksi dan konstruksi bangunan, renovasi, rekonstruksi, dan restorasi rumah, transportasi, aktifitas dalam dan luar rumah serta pengkondisian ruang. Keterkaitan antara rancangan dan aktivitas manusia didalam dan diluar bangunan saling mempengaruhi terbentuknya perumahan berkelanjutan utamanya melalui emisi $\mathrm{CO}^{2}$ yang dihasilkan.Data yang dikumpulkan terutama berkaitan dengan semua komponen sistem lingkungan penunjang kehidupan perumahan sederhana berkelanjutan yaitu; utilitas perumahan seperti; air bersih, gas, listrik, telepon;Ruang Terbuka Hijau (RTH); Tempat Pembuangan Sampah Sementara (TPSA); struktur ruang, jalan dan saluran, serta hirarki jalan; danau buatan; akses; jarak capai; fasilitas-fasilitas sosial, umum, komersil; transportasi umum. 


\subsection{Teknik Pengumpulan Data}

Data-data adalah gambaran kualitatif hubungan antara penghuni perumahan dengan emisi $\mathrm{CO} 2$ dihasilkan. Analisis fenomenologi dari data responden untuk mendapatkan makna melalui pengalaman responden tentang mengapa semua komponenlingkungan penunjang kehidupan perumahandi Perumahan Martubung I berinteraksi menciptakan perumahan sederhana berkelanjtan. Seluruh data dianalisis secara kualitatif, disajikan dalam bentuk narasi (deskripsi), matriks, diagram, dan flowchart (diagram alir).

Pengumpulan data dilakukan dengan cara; Teknik Observasi merekam jejak fisik komponen penunjang kehidupan:utilitas perumahan; fasilitas perumahan; ruang terbuka hijau (RTH); danau buatan; akses; jarak capai; fasilitas-fasilitas komersil, umum, sosial; transportasi umum; elemen lanskap, masyarakat sekitar, danlingkungan sekitar; Teknik Wawancaraterutama gambaran persepsi, pengalaman, perilaku penghuni, keinginan ataupun pandangan penghuni terhadap perumahan sederhana berkelanjutan; Teknik Pengumpulan Data dan Dokumen.

\subsection{Penentuan Lokasi Penelitian}

Data-data Lokasi penelitian ini adalah di Perumahan Griya Martubung I, Kelurahan Besar, Kecamatan Medan Labuhan seperti tampak pada Gambar 1.

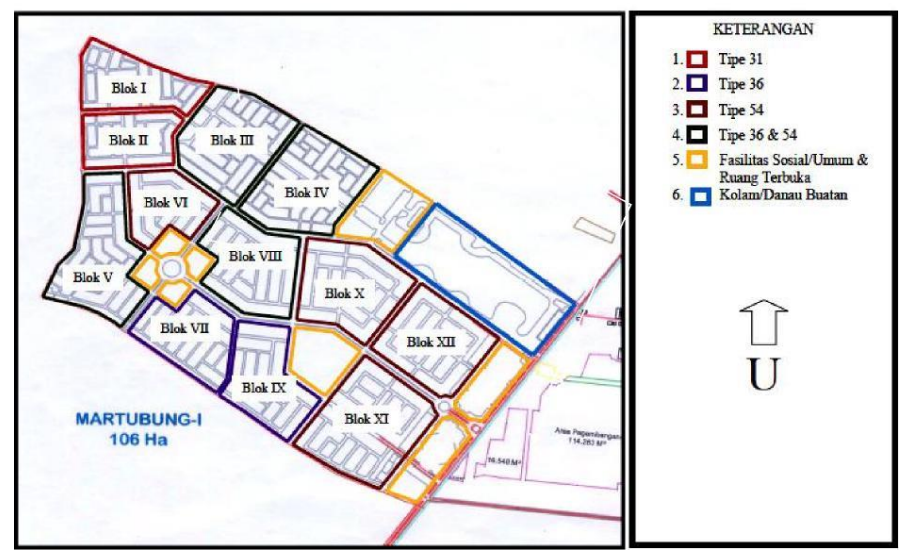

Gambar. 1. Lokasi Perumnas Martubung I Medan

\subsection{Penentuan Populasi dan Sampel Penelitian}

Populasi mencakup: rumah dan penghuni rumah di Perumnas Martubung I. Dua jenis sampel ditentukan yaitu: sampel rumah dan sampel penghuni rumah. Sampel rumahdibatasipada tipe rumah mewakili standar rumah sederhana yaitu; RSh 29, RSh 36, RS 36, dan RS 54.Data perubahan rumah: semua tipe rumah baik yang mengalami restorasi, renovasi, rekontruksi serta rumah yang tidak mengalami perubahan.

Pengambilan sampel penghuni rumah dilakukan untuk memperoleh data-data seperti;data-data dasar, data-data sosial, budaya, dan ekonomi serta data profil perubahan dan kehidupan. Wawancara dan observasi dilakukan dengan menggunakan teknik - purposive sampling dimanapopulasi penghuni ditentukanmenurut blok rumahyang ada di Perumnas Martubung I.128 unit sampel rumah dipilih acak mewakili tipe, lokasi, dan jenis perubahan. Kuesioner dan observasi dilakukan untuk mendapat gambaran dinamika kehidupan perumahan. Observasi dilakukan dengan menghitung langsung rumah untuk mendapat data jumlah rumah mengalami restorasi, renovasi, dan rekonstruksi dan dilakukan pada 12 (dua belas) blok yang ada.

\subsection{Pengolahan Data dan Analisa}

Data-data disajikan dalam bentuk; model matriks, grafik-grafik, diagram-diagram, jaringan kerja, serta bagan. Berbagai data kualitatif kemudian disusun dalam pola hubungan memperlihatkan kaitan antar komponen sistem lingungan penunjang kehidupan perumahan yang berpengaruh dalam sistem perumahan sederhana berkelanjutan sesuai tujuan penelitian. 
Pengumpulan data primer dilakukan secara langsung menggunakan kuesioner berstruktur untuk menjaring/merekam kondisi rumah khususnya dalam hal penggunaan bahan bangunan, penggunaan moda transportasi dalam menunjang aktivitas sehari-hari, besaran energi rumah tangga serta pengkondisian ruang. Dari pengumpulan data tersebut, hanya tiga faktor yang erat dengan penggunaan moda transportasi, besaran energi rumah tangga serta pengkondisian ruang diduga merupakan faktor utama penyumbang terbesar emisi CO2. Proses pengolahan data dilakukan dengan menggunakan SPSS.

Analisis dilakukan terhadap sarana yang menunjang kehidupan seperti; tempat kerja, sekolah, pasar, supermarket, dan rekreasi. Dengan menggunakan data serta kondisi siteplan, maka 12 (dua belas) blok perumahan diperbandingkan. Emisi $\mathrm{CO} 2$ akibatdari aktivitas perjalanan, jarak tempuh, moda dan waktu tempuh memberigambaran perilaku penggunaan bahan bakar sesuai dengan kondisi dan kebiasaan masyarakat. Disisi lain pembahasan belum memperhitungkan reduksi akibat penghijauan perumahan. Penelitian ini dilakukan hanyauntuk perumahan sederhana terencana, dihuni kelompok masyarakat berpenghasilan menengah bawah. Dengan demikian pola dan kebiasaan yang berkaitan dengan hal frekwensi perjalanan yang dilakukan, serta penggunaan energi rumah tangga berkorelasi pula dengan pendapatan.

\section{Hasil dan Pembahasan}

Sejalan dengan dinamika kehidupan diperumahan berbagai motif melatarbelakang iperubahan fisik terjadi di perumahan ini. Perubahan ini menghasilkan emisi CO2 sebagai akibat bertumbuh dan berkembang tuntutan kehidupan perumahan perkotaan. Berbagai konteks dan karakter penghuni perumahan merupakan faktor penting terjadinya berbagai dinamika dan perubahan fisik ini dan selanjutnya mempengaruhi perumahan berkelanjutan. Data dari tahun 1995 sampai dengan tahun 2016menunjukkan bahwa $87 \%$ rumah atau sama dengan sejumlah 2873 unit rumah melakukan berbagai perubahan baik; restorasi, renovasi, maupun rekonstruksi.

Observasi yang dilakukan pada bulan Juli 2016 menunjukkan, rumah tipe kecil seperti tipe 29 dan tipe 36 cenderung melakukan perubahan karena tidak dapat lagi menunjang kebutuhan aktifitas keluarga terutama untuk ruang tidur anak yang membutuhkan 2 (dua) kamar tidur daripada rumah tipe yang lebih besar seperti tipe 54 [1]. Selain itu, penambahanluasrumahsepertipadatipe 29 dilakukankarenaluasrumahtipe 29 memang dibawah standar minimal luas rumah yang diatur dalam Undang-Undang Perumahan dan Kawasan Permukiman No.1 tahun 2011 yaitu $36 \mathrm{~m} 2$. Tabel1 memperlihatkan matriks hubungan antara rumah dengan penghuni rumah dan perubahan rumah yang dilakukan penghuni rumah.

Akses ke perumahan melalui pintu TOL Belmera dan Kawasan Industri Medan (KIM) adalah salah satu komponen penunjang kehidupan dalam mendorong mobilitas dari dan kesekitar perumahan. Tingginya mobilitas dari dan keluar perumahan ini berkontribusi meningkatkan emisi CO2. Ketiadaan fasilitas trotoire meningkatkan ketergantungan penggunaan kendaraan bermotor walau jarak capai masih dalam jarak nyaman bagi pejalan kaki. Perumahan ini tergantung pada transportasi public dan transportasi pribadi. Transportasi public perumahan hanya tergantung pada angkutan kota jenis "mini bus" dengan 6 (enam) arah tujuan kekota Medan dan Belawan melintas di dalam kawasan perumahan ini.

Sistem utilitas perumahan adalah salah satu komponen bagian yang mempengaruhi konsumsi energi dan emisi $\mathrm{CO} 2$. Satu sisi arus kendaraan maupun arus pejalan kaki di perumahan adalah bagian dari pola arus manusia di sisi lain, utilitas juga merupakan arus energi, air, sampah dan sanitasi yang menghasilkan emisi CO2 ke udara. Sistem utilitas di Perumnas Martubung I seperti; pengelolaan sampah,sanitasi, dan drainasebelum direncanakan dandikendalikansebagaimana mestinya. Tempat pembuangan sampah sementara masih sekedar menempati tanah kosong di antara blok IV dan blok VIII.

Oleh karena itu, sistem sanitasi, drainase, dan pengelolaan sampah masih membutuhkan energi dalam proses pembuangan dan berdampak pada peningkatan emisi CO2 
Tabel. 1. Matriks Keterkaitan Antara Penghuni Rumah Dengan Perubahan Rumah Yang Terjadi di Perumahan Griya Martubung I Medan

\begin{tabular}{|c|c|c|}
\hline $\begin{array}{c}\text { Faktor- faktor yang } \\
\text { mempengaruhi }\end{array}$ & Pengaruh pada Rumah & Perubahan yang dilakukan Penghuni \\
\hline $\begin{array}{l}\text { Kualitas bahan bangunan } \\
\text { umumnya rendah dan } \\
\text { tidak } \\
\text { memiliki standar }\end{array}$ & $\begin{array}{l}\text { Sering melakukan } \\
\text { penggantian material } \\
\text { bangunan serta kualitas } \\
\text { pelaksanaan rendah }\end{array}$ & $\begin{array}{l}\text { Penghuni rumah melakukan restorasi rumah, } \\
\text { yaitu dengan menggantikan material } \\
\text { bangunan }\end{array}$ \\
\hline $\begin{array}{l}\text { Rancangan Rumah } \\
\text { tidak sesuai keinginan } \\
\text { dan kebutuhan } \\
\text { penghuni }\end{array}$ & $\begin{array}{ll}\text { - } & \text { Kualitas struktur bangunan } \\
\text { - } & \text { Tidak memenuhi kebutuhan } \\
& \text { ruang } \\
\text { - } & \text { Kebutuhan ruang meningkat } \\
\text { - } & \text { Kenyamanan didalam rumah } \\
& \text { semakin ber kurang }\end{array}$ & $\begin{array}{l}\text { - Melakukan renovasi mengganti } \\
\text { strukturr umah } \\
\text { - Reposisi fungsi ruang misalnya } \\
\text { memindah dapur, kamar mandi } \\
\text { - Penambahan luas ruang } \\
\text { - Menata ulang jendela, ventilasi dlsbnya }\end{array}$ \\
\hline $\begin{array}{l}\text { Pelaksanaan Konstruksi } \\
\text { Rumah tidak memenuhi } \\
\text { Standar Bangunan }\end{array}$ & $\begin{array}{l}\text { - } \quad \text { Kualitas struktur buruk } \\
\text { - } \quad \begin{array}{l}\text { Penghuni ingin struktur yang } \\
\text { baru }\end{array}\end{array}$ & $\begin{array}{l}\text { - Rekonstruksi rumah, rumah sama } \\
\text { sekali beda dari bangunan asli (bentuk } \\
\text { awal) }\end{array}$ \\
\hline
\end{tabular}

Ruang Terbuka Hijau bersama dengan jalan dan saluran adalah merupakan bagian dari fasilitas lingkungan penunjang kehidupan di Perumnas Martubung I. Sebagai public space, RTH di perumahan ini banyak digunakan untuk kegiatan ruang luar seperti olahraga dan taman bermain. Peraturan Menteri Kehutanan No. 3/MenhutV/2004tentang pedoman dan petunjuk pelaksanaan penyelenggaraan Gerakan Nasional Rehabilitasi Hutan dan Lahan serta juga UU No.26 tahun 2007, pasal 28 dan pasal 29 mempersyaratkan perumahan untuk menyediakan jalur hijau sepanjang jalan. Persyaratan jalur hijau ditujukan agar RTH adalah merupakan bagian penanggulangan peningkatan emisi CO2. Secara kuantitas RTH pada perumahan ini bersama jalan dan saluran serta Kolam/danau buatan ada sebanyak $31 \%$ (Tabel. 2).

Tabel. 2. Peruntukan Lahan di Perumahan Griya Martubung I, Medan

\begin{tabular}{|c|c|c|}
\hline Peruntukan & Luas $\left(\mathrm{m}^{2}\right)$ & Prosentase \\
\hline Perumahan & 588.720 & 50 \\
\hline Komersil & 220.840 & 19 \\
\hline Fasilitas sosial & 36.399 & 3 \\
\hline Jalan dan saluran & 257.037 & 22 \\
\hline Ruang terbuka hijau & 35.735 & 3 \\
\hline Kolam & 88.300 & 8 \\
\hline T O T A L & 1.188 .031 & 100 \\
\hline
\end{tabular}

Sumber: Perumnas Regional I (2016) 
RTH di perumahan ini umumnya berupa taman di tiap blok, danau buatan, juga jalur hijau di sepanjang jalan, dan ruang hijau di halaman rumah. Beberapa RTH memberi gambaran RTH tidak sesuai fungsinya seperti di Jl. Rawe Raya berubah menjadi Pasar Sore. Taman lingkungan pada bundaran di blok V, blok VI, blok VII, dan blok VIII digunakan sebagai warung kopi. Lebih jauh, taman pada beberapa blok rumah sering berubah sebagai tempat menjemur pakaian. Kombinasi antara RTH dengan danau buatan di perumahan ini dapat mencegah dan menanggulangi peningkatan emisi CO2 sekaligus menciptakan iklim mikro setempat. Oleh karena itu, keberadaan kedua komponen ini menunjang terbentuknya lingkungan perumahan sederhana perkotaaan berkelanjutan rendah emisi CO2.

Studi ini menunjukkan bahwa interrelasi komponen-komponen sistem lingkungan penunjang kehidupan di Perumnas Martubung I seperti; utilitas perumahan, struktur ruang, jalan dan saluran, hirarki jalan, RTH, danau buatan, akses, jarak capai, fasilitas-fasilitas sosial, umum, dan komersil, serta transportasi berkontribusi meninciptakan rumah berkelanjutan. Sistem utilitas merupakan bagian dari sistem sirkulasi perumahan agar lingkungan perumahan efisien. Selain itu, utilitas perumahan juga merupakan fungsi dari aksesibilitas yang mempengaruhi konsumsi energi dan emisi CO2. Agar efisiensi penggunaan energitercapaimaka aktifitas penghuni harus sejalan dengan daya dukung sistem sirkulasi perumahan. Aliran sistem sirkulasi dari pola-pola aktifitas perumahan ini seperti; pergerakan manusia, barang, sampah, jasa dan informasi umumnya menggunakan kenderaan bermotor baik kendaraan umum maupun pribadi sehingga mengkonsumsi energi dan menghasilkan emisi CO2.

Selanjutnya studi ini juga menunjukkan orientasi pengembangan kehidupan penghuni rumah bersifat kuantitatif ketimbang kualitatif yang diindikasikan melalui perubahan bentuk rumah seperti; restorasi, renovasi, dan rekonstruksi. Perubahan ini membutuhkan energi dan berbagai sumber daya tidak terbarukan. Tabel.3.3 memperlihatkan aspek-aspek dominan mempengaruhi perilaku dan gaya hidup dengan perubahan rumah di Perumnas Martubung I dalam menghasilkan emisi CO2. Salah satu faktor mempengaruhi perubahan rumah adalah meningkatnya kebutuhan ruang penghuni rumah karena dinamika kehidupan yang terjadi. Sementara, rumahtipe 36 dengan luas $36 \mathrm{~m} 2$ untuk penghuni 4 (jiwa) ternyata tidak dapat memenuhi kebutuhan ruang keluarga ideal dengan dua anak. Kebutuhan ruang ideal per kapita menurut Perserikatan Bangsa-Bangsa adalah $10 \mathrm{~m} 2$. Oleh karena itu, penyelenggaraan Perumahan Griya Martubung I tidak sesuai dengan asas dan tujuan seperti dimaksud pada BAB II pasal 3 butir f dari Undang-Undang Republik Indonesia Nomor 1 Tahun 2011 tentang Perumahan dan Kawasan Permukiman yaitu untuk menjamin terwujudnya rumah layak huni dan terjangkau dalam lingkungan yang sehat, aman, serasi, teratur, terencana, dan berkelanjutan.

Tabel. 3. Matriks perilaku dan gaya hidup dengan perubahan rumah dalam menghasilkan emisi CO2di Perumahan Griya Martubung I Medan

\begin{tabular}{|c|c|c|c|}
\hline No. & Aspek & Respon & Perubahan yang dilakukan Penghuni Rumah \\
\hline 1 & Identitas diri & $\begin{array}{l}\text { memperkenalkan diri melalui } \\
\text { keberadaan rumah pribadi }\end{array}$ & $\begin{array}{l}\text { restorasi/renovasi rumah menggunakan berbagai } \\
\text { material baru }\end{array}$ \\
\hline 2 & Gaya hidup & $\begin{array}{l}\text { pemahaman baru tentang } \\
\text { hubungan manusia dan } \\
\text { lingkungannya }\end{array}$ & $\begin{array}{l}\text { melakukan reposisi fungsi ruang tertentu } \\
\text { misal; dapur, kamar mandi. }\end{array}$ \\
\hline 3 & Teknologi & $\begin{array}{l}\text { menggunakan berbagai alat } \\
\text { rumah tangga dengan teknologi } \\
\text { baru }\end{array}$ & $\begin{array}{l}\text { renovasi dan rekonstruksi menggunakan teknologi } \\
\text { berbasis energi tak terbarukan }\end{array}$ \\
\hline 4 & Sosial budaya & $\begin{array}{l}\text { perubahan gaya rumah } \\
\text { akibat perubahan sosial } \\
\text { budaya }\end{array}$ & $\begin{array}{l}\text { mengubah ruang dengan } \\
\text { perluasan bangunan }\end{array}$ \\
\hline 5 & Ekonomi & $\begin{array}{l}\text { faktor dominan dalam mendorong } \\
\text { berbagai perubahan fisik rumah }\end{array}$ & $\begin{array}{l}\text { perkembangan ekonomi, melakukan } \\
\text { rekonstruksi rumah sama sekali baru }\end{array}$ \\
\hline
\end{tabular}




\section{Kesimpulan}

Studi ini menunjukkan bahwa kontribusi sistem lingkungan penunjang kehidupan perumahan dalam menciptakan perumahan sederhana berkelanjutan ternyata bukan hal yang dapat terwujud begitu saja. Perumahan sederhana rendah berkelanjutan dapat tercipta hanya apabila karakteristik sosial-budaya masyarakat kota Medan pada umumnya dan penghuni Perumahan Martubung I pada khususnya dapat sejalan dengan seluruh aspek pemanfaatan ruang perumahan ini. Persoalan karakteristik sosial-budaya dalam upaya peningkatan emisi CO2 di Perumahan Martubung I tidak terlepas dari gaya hidup dan perilaku penghuni perumahan. Berbagai pilihan dan kebutuhan masyarakat yang lahir melalui proses-proses sosial-budaya di perumahan ini umumnya terkait dengan kondisi lingkungan perumahanyang ada.

Berbagai faktor penting berpengaruh positif terhadap pembentukan perumahan sederhana berkelanjutan utamaya adalah sarana prasana, danau buatan dan RTH . Akan tetapi, gaya hidup dan perilaku penghuni perumahan melahirkan masyarakat yang tergantung pada pemakaian energi tak terbarukan sering mengakomodasi peningkatan emisi CO2 di perumahan Martubung I Medan.

\section{Referensi}

[1] Afiaty, D. F. (2003). "Faktor-faktor Penentu Pemilihan Tipe Rumah dan Implikasinyaterhadap Tingkat Kepuasan Pemilik serta Jenis dan Frekuensi Perubahan Rumah:Perumnas Sarijadi Bandung”. Tesis Program Magister, Institut Teknologi Bandung.

[2] Astuti, (2005). "Pengaruh Rancangan Ruang Kawasan Perumahan Perkotaan Terhadap Emisi CO2, Makalah Seminar, Lokakarya Temu Kenali Faktor-Faktor Penentu Emisi CO2 Menuju Kearah Terbentuknya Pemukiman Perkotaan".

[3] Bhatti, M., Dixon, A. (2003). "Introduction to the Special Focus: Housing, Environment, and Sustainability, Housing Studies 18, pp. 501-504.

[4] Budihardjo, E.,Sujarto, D.(2005).Kota Berkelanjutan, Alumi, Bandung.

[5] DeTombe Dorien, (2014). Handling Societal Complexity, A study of the Theory of the Methodology of Societal Complexity and the COMPRAM Methodology, Springer, Amsterdam.

[6] Dewi, I.K, Sudjono, P. (2007). Penggambaran Dalam Sistem Terhadap Fakor-Faktor Penentu Emisi CO2 Pada Pembangunan Rumah dan Kehidupan di Kampung Naga, Program Studi Teknik Lingkungan, ITB.

[7] Firth, S. K., Lomas, K.J. (2009). Investigating CO2 Emission Reductions In Existing Urban Housing Using Community Domestic Energy Model, 11th International IBPSA Conference, Glasgow, Scotland.

[8] Herawati, P. (2010). Analisa Komponen Penentu Emisi CO2 Dari Dinamika Perubahan Rumah Dalam Sistem Kehidupan Perkotaan di Perumnas Sarijadi Bandung, Thesis, Institut Teknologi Bandung.

[9] Indonesia, (2007).Pusat Penelitian dan Pengembangan Pemukiman Departemen Pekerjaan Umum, Keterkaitan Penyelenggaraan Bangunan dengan Emisi CO2.

[10] Jabareen, Y. R. (2006). Sustainable Urban Forms, Their Typologies, Models, and Concepts, Journal of Planning Education and Research.

[11] Klunder, G. The search for the most eco-efficient strategis for sustainable housing construction; Dutch lessons, Delf University Of Technology, dapat di aksesdarig.klunder@otb.tudelft.n

[12] Montgomery, R., Stern, R., Cohen, B., Reed, H. E. (2003). Cities transformed: demographic change and its implications in the developing world, Washington, DC: The National Academic.

[13] Octaviana, C.Y., Sudjono, P., Dewi, I.K. (2007). Analyses on Life in Kampong Naga to Deduce Policy on Carbon-Dioxide Emitted from House Contruction, Lab. Of Computational Mechanics on Environmental System, Dept. Of Environmental Engineering Bandung Institute of Technology.

[14] Priemus, H. (2005). (2005). How To Make Housing Sustainable? The Dutch Experience, Environment and Planning: Planning and Design, 2005 vol. 32, pp. 5-19.

[15] Siahaan, N. (2012). Model Pengendaliaan Perumahan Sederhana Dalam Sistem Perumahan Berkelanjutan Perkotaan Berbasis Rendah Emisi CO2. Disertasi Doktor, USU, 2012. 
[16] Suhedi, F. (2007). Emisi CO2 dari Konsumsi Energi Domestik, makalah Seminar Pusat Penelitian dan Pengembangan Pemukiman. 